\title{
Influence of polymorphisms in the gene ACTN3 R577X in power athletes
}

\begin{abstract}
Many researches are starting to link the sporting prowess of some nations on the polymorphism of the ACTN3 gene, said to be responsible for the encoding of the $\alpha$-actinin protein. A consensus on the subject has yet to be reached, and this study aims to account the opinions and analyze some points.
\end{abstract}

Keywords: power athletes, polymorphism, ACTN3 R577X, sports, genetics, $\alpha$-actinin

\author{
Volume 5 Issue 3 - 2017 \\ Carlos Eduardo S Dos Santos,' Derllon \\ Jackson GA Corrêa,' Otávio De Oliveira \\ Lopes,' Rodrigo Moraes, ${ }^{2}$ Rodrigo Pratte \\ Santos ${ }^{1,3}$ \\ 'Biomedic, Pio XII College, Brazil \\ ${ }^{2}$ Pharmaceutical, Pio XII College, Brazil \\ ${ }^{3}$ Federal University of Espirito Santo, Brazil
}

\begin{abstract}
Correspondence: Rodrigo Pratte-Santos, Pio XII College, Bolívar de AbreuSt, 48- Campo Grande- Cariacica, Espirito Santo, Brazil,Tel +55(27) 342I2563,

Email rodrigopratte@outlook.com
\end{abstract}

Received: November 04, 2016 | Published:March 02, 2017

\section{Introduction}

Since the beginning of the era of genetic research, started by Gregor Mendel in 1866, big leaps were made towards the relationship between each function of the body and its respective genetic information, and with that the idea that above average athletes had in their genome the source of their abilities. The first study exploring this relationship was published in the late 60 's, and since 2001 some athletic entities such as WADA (World Antidoping Agency) and IOC (International Olympic Committee) have recognized and discussed the influence of "gene doping", which refers to some therapies aimed to increase or decrease the expression certain proteins linked to high performance sports. ${ }^{1}$ Now the focus has turned to the $\alpha$-actinin protein, expressed in the Z-line of the sarcomere in skeletal muscles. This protein acts in the maintenance of the myofibrillar matrix, and exists in the two main forms, $\alpha$-actinin- 2 and $\alpha$-actinin- 3 , the first one being expressed in all skeletal muscles and the second mainly on fasttwitch type II fibres. ${ }^{2}$ Aside from its role in the structural maintenance of the sarcomere of the type II fibres, $\alpha$-actinin- 3 is also involved with several metabolic pathways, contributes to the growth of more type 2 fibres and alters glycose catabolism as an answer to certain stimulus. ${ }^{3}$ The gene responsible for the $\alpha$-actinin- 3 is the ACTN3, and exists in three different genotypes, $\mathrm{RX}$ (also known as $\mathrm{C}$; $\mathrm{T}$ in some articles), $\mathrm{XX}$ (or T;T) and RR (or $\mathrm{C} ; \mathrm{C}$ ), where individuals with the $\mathrm{C}$; $\mathrm{T}$ genotype show a deficiency in the synthesis of $\alpha$-actinin-3 while T;T homozygote's are completely unable to synthesise the protein (instead using $\alpha$-actinin-2 in all fibres) and the C;C genotype show a full expression of the protein, and constitute only $18 \%$ of the general population. ${ }^{4}$ The deficiency or complete inability to synthesise $\alpha$-actinin-3 have no know consequence to the individual, although some articles link it to an increased difficulty in sports, showing that the proportionality between population and elite level athletes doesn't hold true. On the proteic level, the difference is observed in the 577 position of the $\alpha$-actinin-3. In the R variant of the ACTN3, a cytosine leads to the encoding of a arginine while the $X$ variant encodes a stop codon, considered to be premature and renders the protein useless.
The aim of this study was to evaluate the Influence of polymorphisms in the gene ACTN3 R577X in power athletes.

\section{Methodology}

Every bibliographic research of manuscripts involving the ACTN3 R577X gene and athletes were made using PubMed and Science Direct. The key-words "ACTN3", "polymorphisms" and "power athletes" were used in every field for scientific journals. The period analysed was since 2010 to 2016 . Were selected the publications containing the following information: (I) year of publication; (II) author names; (III) type of study (paper, experimental research, review article); (IV) field of science (V) journal name; (VI) key-words; (VII) institutions to which the authors are affiliated and (VIII) countries were the studies were conducted.

Only works published in English were used, with original data analysing the aspects of the supposed relationship between the polymorphisms of the ACNT3 R577X in athletes. Review articles and articles without original experimental results were excluded. The article selection was done initially with reading the titles and abstracts, and then the methodologies were read, the non-relevant articles were excluded. After the reading and interpretation, the information was organized in thematic groups. Because of its reviewing nature, this article did not have to pass through any ethics committee. The impact factors of the journals used were obtained using the SCI Journal Impact Factor (http://www.bioxbio.com/if/).

\section{Discussion}

The article search through Science Direct and PubMed returned 37 and 39 results, respectively. The first graph shows the relation between year and number of publications, per database (Figure 1). Unfortunately, a big number of articles weren't related directly to this study's area, or were duplicated, or had other characteristic that made them unfit for this review, and were excluded, as shown in Figure 2 below. 


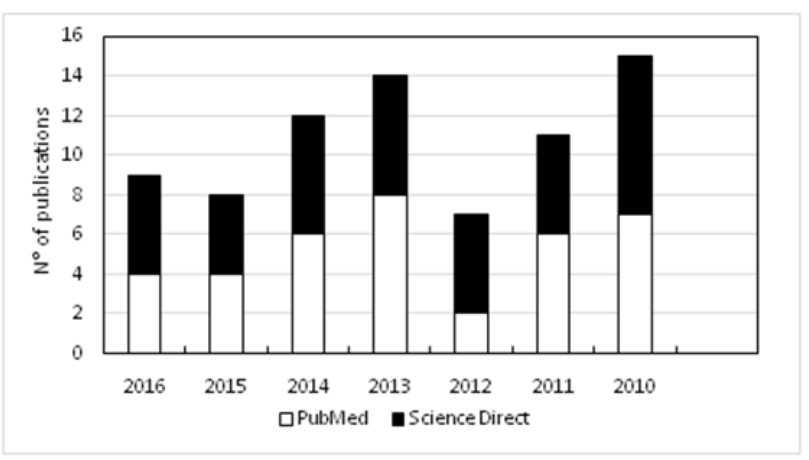

Figure I Publications per year and database.

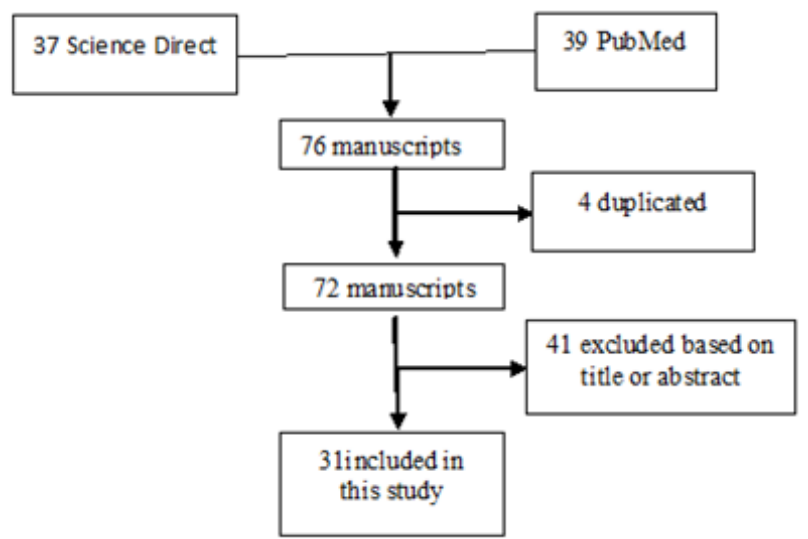

Figure 2 Exclusion diagram of the used manuscripts in this study.

The analysis of the conclusion of the articles revealed a division about the conclusion reached by the statistical analysis (Chi-square test, $p>0.05$ ) of the manuscripts between the ones who agreed and the ones who disagreed with the idea that the RR genotype positively influenced the explosive muscular performance while the $\mathrm{XX}$ increased the resistance of the athletes, as shown in Figure 3. Four $(12.9 \%)$ of the analysed articles did not agreed nor disagreed, instead exposing arguments to both sides, and were labelled "moderate" in the graph.

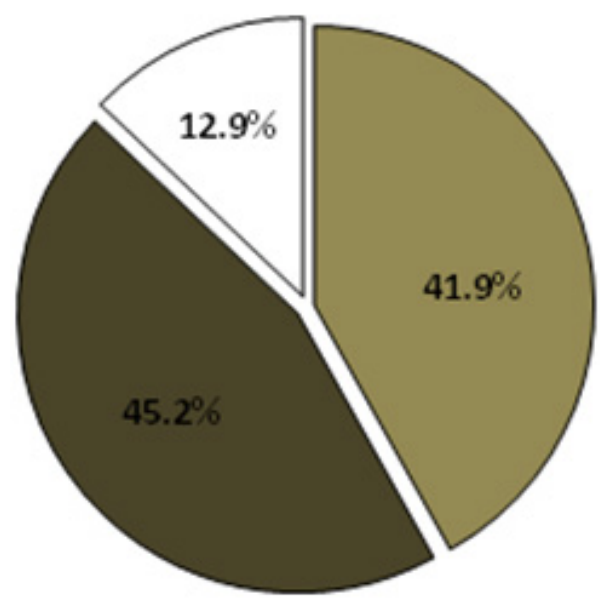

\section{$\square$ Agreed $\square$ Disagreed $\square$ Moderate}

Figure 3 Conclusion about the influence of the genotype on muscle performance.
The Figure 4 shows the relationship between the conclusion of each article and their impact factors. This does not include the "Sports Medicine Open" Journal, where "ACTN3 Polymorphism: Comparison between Elite Swimmers and Runners" $" 5,6$ was published, since it does not have a published impact factor. There was no significant difference $(\mathrm{p}=0.8588)$ between the impact factors of the journals that accepted or rejected the hypothesis of the influence of ACN3 R577X gene in the performance of high-performance athletes.

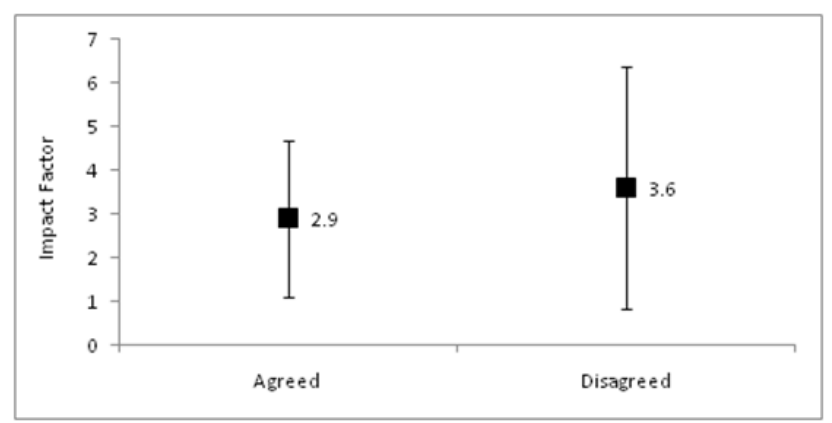

Figure 4 Relationship between impact factors and the conclusion reached. The $\mathrm{p}$-value was established by Mann-Whitney test.

Between the "moderate" manuscripts, ${ }^{6}$ reported that their raw strength test, performed with 85 people, did not achieved a significant difference. However the dynamic movement test showed a perceptive difference between genotype, suggesting that $\alpha$-actinin- 3 may be more involved with dynamic movement. ${ }^{7}$ Brings another view to the subject, and connects the bone density in rats with the ACTN3 genotype and concludes that the correlation exists, reporting that rats that had the XX genotype (and thus were unable to synthesise $\alpha$-actinin-3) showed bone density significantly reduced.

Between the studies that agreed with the idea, the biggest impact factor comes from. ${ }^{8}$ That analysed 456 Russian athletes and 1211 controls. The article reported that the proportion between genotype of the general population and the genotype of the athletes did not hold $(14.5 \%$ of the general population had XX genotype while only $5.7 \%$ of the athletes had) and having the $\mathrm{X}$ allele influenced in the performance results, as shown in Table 1. Also, the study reported that between the elite level athletes, none had the XX genotype. On the contrary side, the most important work comes from. ${ }^{9}$ that analysed 211 Japanese athletes, 77 of them of regional level, 72 from the national level and 62 elite level, international athletes, comparing them to 649 controls in resistance and explosive racing tests, and reports no significant results. ${ }^{10}$

Table I Relationship between genotype and timing in rowing. Results presented in seconds $[8$, modified]

\begin{tabular}{ll}
\hline Genotype & Result \\
\hline $577 R R$ & 1339 \\
$577 R X$ & 1386 \\
$577 X X$ & 1402 \\
\hline
\end{tabular}

\section{Conclusion}

The analysis of the studies showed a big division of opinions when it comes to the existence and range of the possible influence of the ACTN3 R577X polymorphism in athletes. It is clear that more studies on the subject must be conducted, not only to establish a definitive connection (or lack thereof) in order to understand the exact mechanisms with which $\alpha$-actinina- 3 affects muscle performance. 


\section{Acknowledgements}

We are grateful to Pio XII College to encourage and promote research activities through the Scientific Initiation Program.

\section{Conflict of interest}

The author declares no conflict of interest.

\section{References}

1. Sawczuk M, Maciejewska A, Cieszczyk P, et al. The role of genetic research in sport. Science \& Sports. 2011;26(5):251-258.

2. Stephen M Roth, Sean Walsh, Dongmei Liu, et al. The ACTN3 R577X nonsense allele is under-represented in elitelevel strength athletes. Eur J Hum Genet. 2008;16(3):391-394.

3. Lucia A, Eynon N, Hanson ED, et al. Genes for elite power and sprint performance: ACTN3 leads the way. Sport Med. 2013;43(9):803-817.

4. Ruiz JR, Gomez Gallego F, Santiago C, et al. Is there an optimum endurance polygenic profile? J Physiol. 2009;587(7):1527-1534.
5. North KN, Yang N, Wattanasirichaigoon D, et al. A common nonsense mutation results in alpha-actinin-3 deficiency in the general population. Nat Genet. 1999;21(4):353-354

6. Orysiak J, Busko K, Michalski R, et al. Relationship between ACTN3 R577X polymorphism and maximal power output in elite Polish athletes. Medicina. 2014;50(5):303-308.

7. Nan Yang, Aaron Schindeler, Michelle M McDonald, et al. $\alpha$-Actinin-3 deficiency is associated with reduced bone mass in human and mouse. Bone. 2011;49(4):790-798.

8. Ahmetov II, Druzhevskaya AM, Astratenkova IV, et al. The ACTN3 R577X polymorphism in Russian endurance athletes. Br J Sports Med. 2010;44(9):649-652.

9. Miyamoto Mikami E, Murakami H, Tsuchie H, et al. Lack of association between genotype score and sprint/power performance in the Japanese population. J Sci Med Sport. 2016;S1440-2440(16):30110-30114.

10. Ben Zaken S, Eliakim A, Nemet D, et al. ACTN3 Polymorphism: Comparison Between Elite Swimmers and Runners. Sports Med Open. 2015;1(1):13. 